\title{
AVALIAÇĀO PRELIMINAR DOS ARGILOMINERAIS DAS FOLHAS DE CAMOBI E SANTA MARIA, RIO GRANDE DO SUL
}

José Luiz Silvério da Silva (Depto. Geociências-CCNE/UFSM)

Egydio Menegotto (Depto. Geociências-CCNE/UFSM)

Edgargo Ramos Medeiros (Depto. Geociências - CCNE/UFSM)

Partindo da linha de pesquisa desenvolvida pelo Departa mento de Geociências da Universidade Federal de Santa Maria, estão em execução os seguintes Projetos: a) Caracterização Geológica-Geo técnica de Formações Sul-Rio-Grandenses, da Região Centro Oeste, b) Estudo do Mesozóico Continental do Rio Grande do Sul.)

Uma vez que o mapeamento geológico, em escala 1:50.000, das Folhas de Camobi e Santa Maria, jā se encontrava concluído, par tiu-se para a realização de estudos mineralógicos da fração fina, menor que 0,002 mm, de rochas sedimentares, de suas alterações, dos solos superficiais, analisando-se amostras em afloramentos.

os estudos em andamento, compreendem: reconhecimento das fácies sedimentares, em escala de campo e em laboratório; dentre es sas análises, tem-se as granulométricas das frações areia, silte e argila; estudos por difração de Raios-X para reconhecimento dos a gilominerais, dos óxidos e dos carbonatos; realizou-se também estụ dos dos minerais pesados em lupa binocular, ao microscópio óptico deĉerminando-se os índices de refração, com o auxílio de um refratô metro, determinação do peso específico com o uso de balanças de pre cisão.

Atē o presente momento, foram analisadas 25 amostras: sen do 2 da Formação Rosārio do Sul; 18 da Formação Santa Maria, destas 13 no Membro Alemoa (superior), e 5 no Membro Passo das Tropas (in ferior); 4 na Formação Caturrita e 1 em solo subatual, rico em maté ria orgânica.

Os argilominerais identificados nestas formações foram, em ordem decrescente de abundância relativa: as esmectitas, as ilitas e as caulinitas. Como minerais acessórios nesta fração, foram reco nhecidos; o quartzo, os feldspatos e as micas.

Estudou-se a ocorrência de argilominerais associados a 2 crostas carbonáticas, que ocorrem no Membro Alemoa, da Formação San ta Maria, em certos locais. Também avaliou-se a mineralogia dos 
veios negros, que cortam estas crostas carbonāticas, analisando-se amostras pulverizadas à pó, em Difração de Raios-X, confeccionou-se lâminas delgadas de 2 crostas carbonáticas, e avaliou-se os índices de refração no microscópio óptico.

A identificação dos grupos de argilominerais foi realiza da atravēs do estudo das reflexões basais. As esmectitas mostraramse expandidas em amostras naturais, com picos (001) entre 14,97 à $16,08 \mathrm{~A}$; as caúlinitas com picos $(001)$ entre 7 até $7,15 \mathrm{~A}$, e picos (002) de 3,59 A; as ilítas com picos $(001)$ entre 10 à $10,32 \AA$ e pi $\cos (002)$ de 5 à $5,12 \AA$.

As esmectitas quando glicoladas, expandem-se para valores médios de $17 \AA$, podendo atingị $17,65 \AA$, enquanto nas amostras cal cinadas, contraem-se para $10 \mathrm{~A}$. O pico (001) das ilitas não sofre alteração, tanto em amostras calcinadas, quanto em glicoladas.

Nas tabelas que se seguem, E representa as esmectitas ex pandidas; I as ilitas, $K$ as caulinitas, $Q \circ$ quartzo, $F$ os feldspa tos, $M$ as micas e Tr os minerais em traços (teores relativos meno res que $0,5 \%$, X indica a presença de minerais acessórios.

TABEIA I. Argilominerais da Fonmação Rosārio do Sul.

\begin{tabular}{clrrrrr}
\hline \multirow{2}{*}{ Amostra } & Textura & Argilominerais & Min. Aces. \\
& & E & I & F & M \\
\hline \multirow{2}{*}{ SS 17} & Arenito médio & 9 & 1 & $\mathrm{X}$ & $\mathrm{X}$ & $\mathrm{X}$ \\
SS 56 & Arenito fino & 10 & $\mathrm{Tr}$ & & $\mathrm{X}$ & $\mathrm{X}$ \\
\hline
\end{tabular}

Da análise da Tabela I, nota-se um amplo predomínio das esmectitas expandidas sobre as ilitas e a não ocorrência de cauli nitas, na Formação Rosārio do sul.

Na Tabela II, são apresentados os argilominerais identifí cados na Formação Santa Maria, onde observa-se no Membro Passo das Tropas, uma predominância relativa das ilitas sobre as esmectitas expandidas e destas sobre as caulinitas. No Membro Alemoa, ocorre uma inversão nos valores relativos de abundâncias, as esmectitas ex pandidas são mais importantes que as ilitas, e nota-se baixos valo. res relativos de ocorrência das caulinitas.

Na Tabela III, são apresentados os argilominerais da Forma ção Caturrita s.s. (ANDREIS; BOSSI e MONTARDO, 1980), onde pode ser notado um amplo predomínio das esmectitas expandidas sobre as ili tas, e ausência de caulinitas nas quatro amostras analisadas.

Pela observação de lâminas delgadas ao microscópio óptico observou-se nas crostas carbonáticas do Membro Alemoa, duas gera ções de calcita, recortadas. por veios negros, de espessura variável, milimétrica, também por minerais calcíticos, identificados pelo seu 
indice de refração 1,658. Nota-se, por esta técnica, que os mine rais calcíticos estão sendo parcialmente substituidos por óxidos ou hidróxidos, que oferecem, possivelmente, a cor preta aos veios. Tambēm foi identificada calcedônia, com extinção ondulante, e ocu pando póros nas crostas carbonáticas.

TABEIA II. Argilominerais da Fonmação Santa Maria.

\begin{tabular}{|c|c|c|c|c|c|c|c|c|c|}
\hline \multicolumn{2}{|c|}{ Amostra } & Textura & \multicolumn{3}{|c|}{ Argilominerais } & $\begin{array}{l}\text { M. } \\
Q\end{array}$ & \multicolumn{2}{|c|}{$\begin{array}{l}\text { Aces. } \\
\mathrm{F} \quad \mathrm{M}\end{array}$} & Membro \\
\hline ss & 2 & Siltito & 7,5 & 1 & 1,5 & $x$ & $\mathrm{x}$ & & Alemoa \\
\hline SS & 10 & Lamito & 5 & 5 & & $\mathrm{x}$ & $\mathrm{x}$ & & Alemoa \\
\hline ss & 20 & Lamito & 10 & $\operatorname{Tr}$ & & $\mathrm{x}$ & $\mathrm{x}$ & $\mathrm{x}$ & Alemoa \\
\hline SS & 45 & Lamito & 10 & $\operatorname{Tr}$ & & $\mathrm{x}$ & $\mathrm{x}$ & & Alemoa \\
\hline SS & 50 & Siltito & 10 & & & $\mathrm{x}$ & $\mathrm{x}$ & & Alemoa \\
\hline SS & 55 & Siltito argiloso & 10 & $\operatorname{Tr}$ & & $\mathrm{x}$ & $\mathrm{x}$ & $\mathrm{x}$ & Alemoa \\
\hline SS & 60 & Lamito & 9 & 1 & & $\mathrm{x}$ & $\mathrm{x}$ & & Alemoa \\
\hline ss & 65 & Lami to & 9 & 1 & & $\mathrm{x}$ & $\mathrm{x}$ & & Alemoa \\
\hline SS & 66 & Lamito & 7,5 & 2 & 0,5 & $\mathrm{x}$ & $x$ & & Alemoa \\
\hline SS & 70 & Lamito & 9 & 1 & & $\mathrm{x}$ & $\mathrm{x}$ & & Alemoa \\
\hline SS & 76 & Lami to micáceo & 7,5 & 2 & 0,5 & $\mathrm{x}$ & $x$ & & Alemoa \\
\hline SS & 86 & Arenito médio & 10 & $\operatorname{Tr}$ & & & $\mathrm{x}$ & & Alemoa \\
\hline SS & 96 & Arenito fino & 10 & $\operatorname{Tr}$ & & $\mathrm{x}$ & $\mathrm{x}$ & & Alemoa \\
\hline SS & 3 & Arenito médio & 10 & & & $\mathrm{x}$ & $\mathrm{x}$ & & P. Trop. \\
\hline SS & 16 & Arenito médio & & 6,5 & 3,5 & $\mathrm{x}$ & $\mathrm{x}$ & & P.Trop. \\
\hline SS & 26 & Lamito & 2 & 6 & 2 & $\mathrm{x}$ & $\mathrm{x}$ & & P.Trop. \\
\hline Ss & 36 & Lamito & 3 & 4 & 2,5 & $\mathrm{x}$ & $\mathrm{x}$ & & P. Trop. \\
\hline SS & 46 & Bola de argila & & 10 & & $\mathrm{x}$ & $\mathrm{x}$ & & P. Trop. \\
\hline ss & 40 & Arenito médio & 8,5 & 0,5 & 1 & $\mathrm{x}$ & $\mathrm{x}$ & & Solo \\
\hline
\end{tabular}

TABELA III. Argilominerais da Formação Caturrita.

\begin{tabular}{llrrrr}
\hline \hline Amostra & Textura & \multicolumn{2}{c}{ Argilominerais } & $\begin{array}{c}\text { Min. } \\
\text { Q }\end{array}$ & $\begin{array}{c}\text { Aces. } \\
\text { F }\end{array}$ \\
\hline SS 15 & Arenito fino & 10 & $\operatorname{Tr}$ & $\mathrm{X}$ & $\mathrm{X}$ \\
SS 25 & Arenito fino & 8 & 2 & $\mathrm{X}$ & $\mathrm{X}$ \\
SS 30 & Arenito fino & 10 & $\operatorname{Tr}$ & $\mathrm{X}$ & $\mathrm{X}$ \\
SS 35 & Arenito fino & 10 & $\operatorname{Tr}$ & & $\mathrm{X}$ \\
\hline
\end{tabular}

Na Figura 1, são apresentados os picos de amostras natú ral, glicolada e calcinada, um siltito amostra ss 2 da Formação San ta Maria, Membro Alemoa. Notar que amostra calcinada o pico de 9,97 $\AA$ é mais intenso do que o da amostra glicolada, o que ocorre devido 
à soma de intensidades dos picos da ilita e esmectita, na amostra calcinada. Na amostra glicolada a esmectita expande-se à 17,21 A, e a ilita, permanece quase inalterada, em relação aos tratamentos, com pico em torno de $10 \mathrm{~A}$.

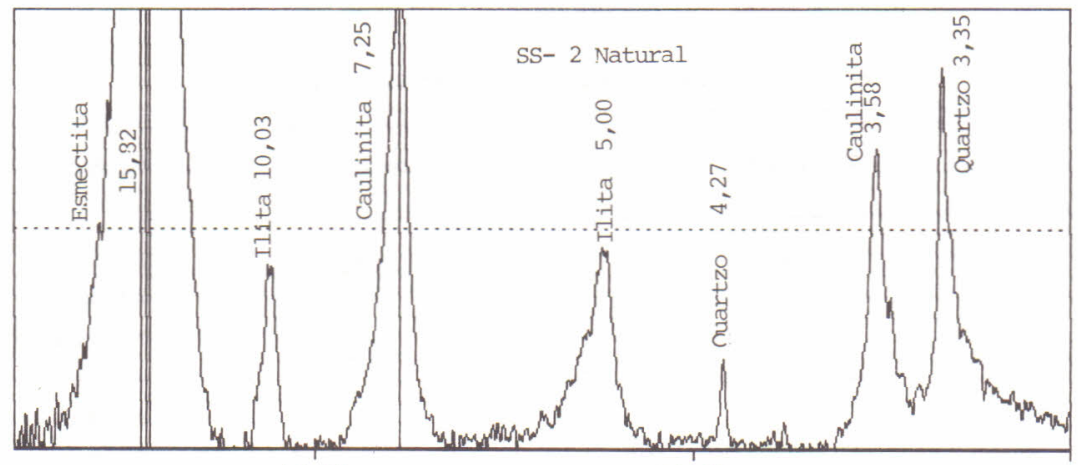

10.00

20.00
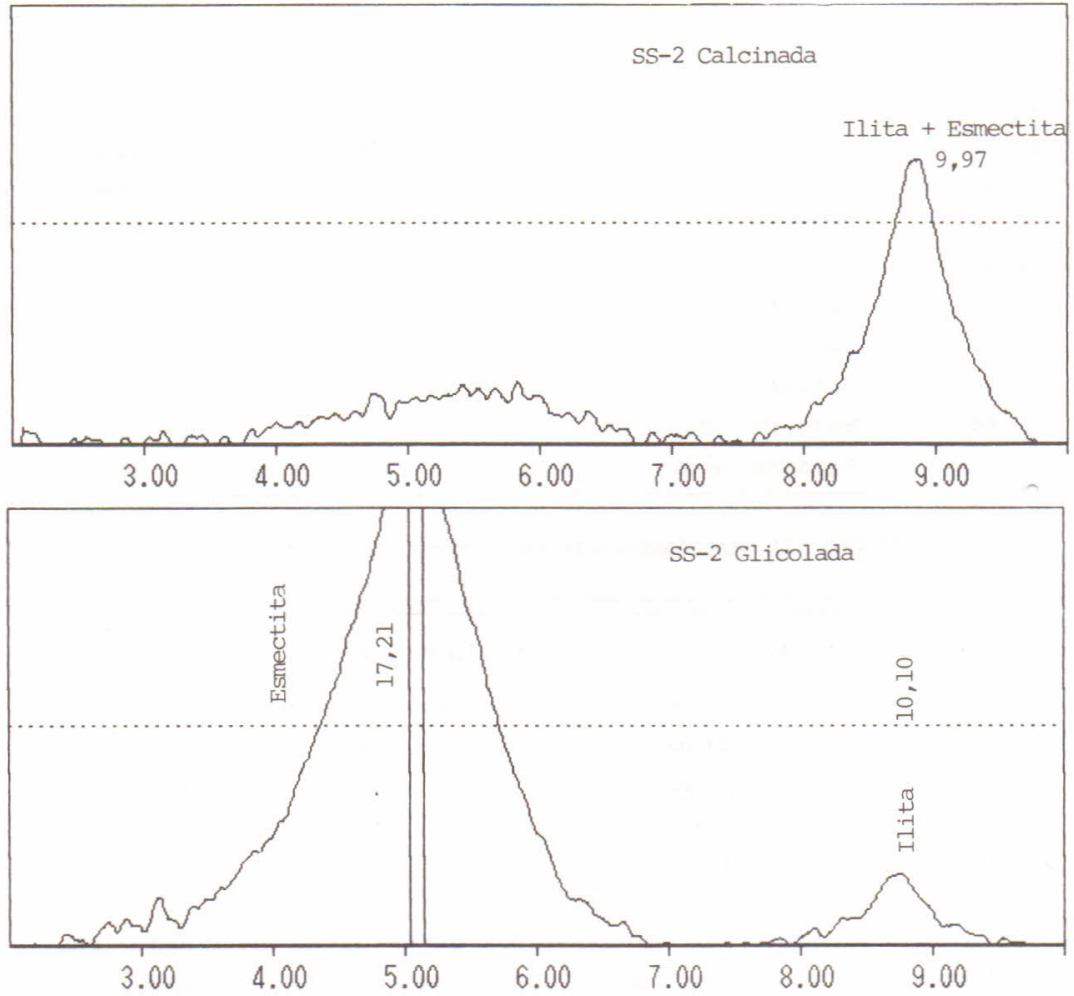

Figura 1. Difratogramas da F. Santa Maria, M. Alemoa. 
Na Figura 2 são mostrados os picos de calcita e quartzo, identificados em duas crostas carbonăticas da Formação Santa Maria, Membro Alemoa. A porção superior desta figura é de amostra coletada no Km-3 da BR-287 na cidade de Santa Maria, enquanto a porção infe rior, corresponde ao material pulverizado do veio negro, de crosta carbonática, coletado em Santa Cruz do Sul, RS-509.

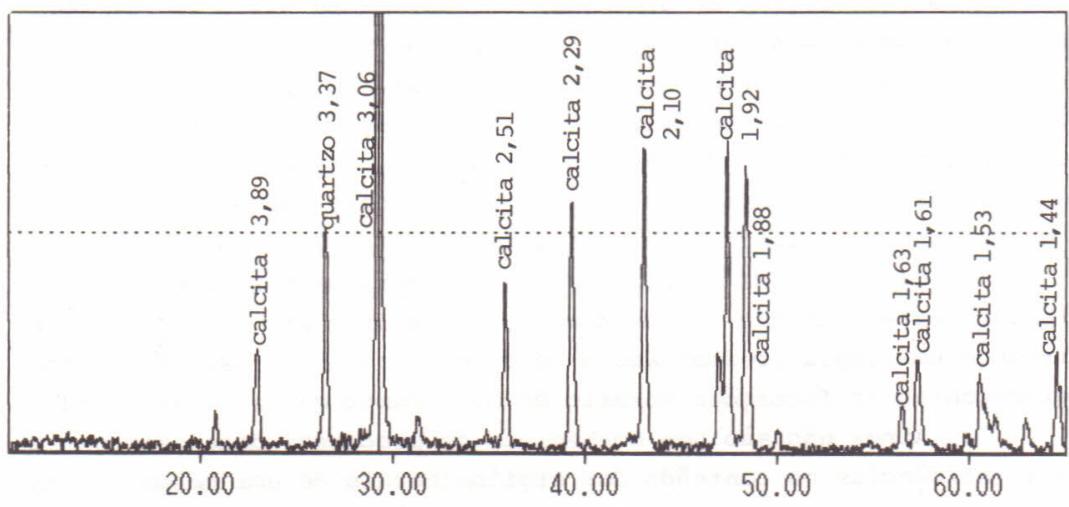

(a)

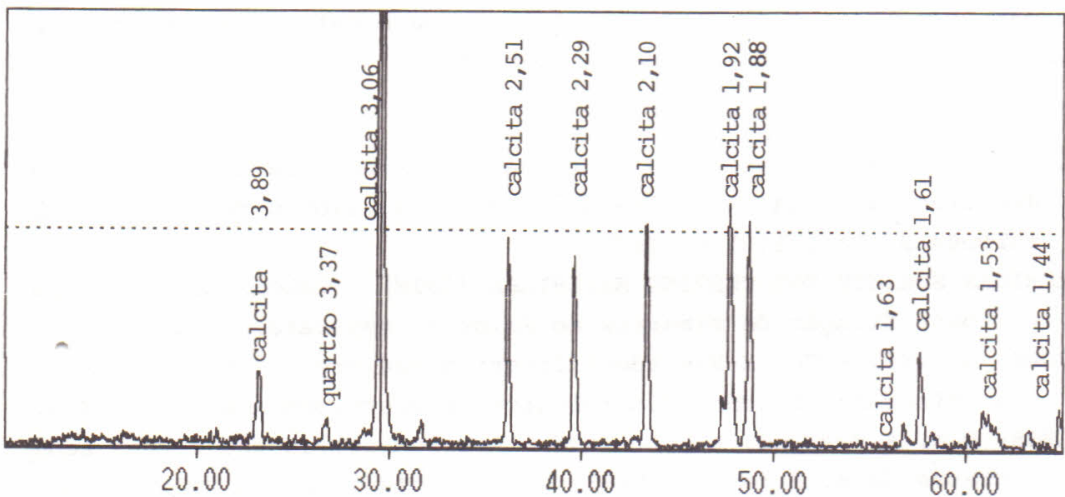

(b)

Figura 2: (a) Formação Santa Maria, Membro Alemoa, Km-3 $\mathrm{Br}-287$.

(b) Formação Santa Maria, Membro Alemoa, RS-509.

Pela observação conjunta da Figura 2, nota-se uma quase perfeita coincidência dos picos identificados, tanto na crosta car bonática quanto no material do veio negro, indicando que ambas as amostras são predominantemente formadas por calcita.

Como conclusões parciais, em relação as pesquisas ante riores, realizadas em rochas sedimentares que se supõe, terem sido 
equivalentes as aqui analisadas, observou-se a presença de caulini tas na Formação Santa Maria, em maiores proporções relativas no Mem bro Passo das Tropas.

GAMERMANN (1979) estudando afloramentos da fácies Santa Maria, na região de Rosário do Sul, MONTARDO (1980) analisando a mes ma formação em Santa Cruz do Sul, bem como VEIGA (1979) estudando esta unidade na região de são Pedro do Sul, Santa Maria e Camobi, tambēm não detectaram caulinitas na Formação Santa Maria.

MONTARDO (1980) encontrou cloritas, em pequenas propor ções, em amostras da Formação Caturrita na região de Santa Cruz do Sul, enquanto VEIGA (1979) analisando a mesma unidade na região de Santa Maria, não identificou este argilomineral, não encontrado atē o momento neste trabalho nas Folhas de Camobi e Santa Maria.

Os grupos de argilominerais encontrados nas formações ana lisadas neste trabalho, concordam com os autores precedentes, con firmando uma ampla predominância de esmectitas e ilitas, em rochas pertencentes as formações Rosário do sul, Santa Maria e Caturrita.

Ainda não são bem conhecidos os processos diagenéticos e suas influências no conteúdo dos argilominerais de uma mesma forma ção sedimentar, bem como os efeitos da tectônica ou mesmo dos pró cessos supergênicos que atuam, próximo a superfície, podendo trans formar localmente a composição química e/ou a estrutura dos argilo minerais presentes em um pacote sedimentar.

\section{REFERENCIAS BIBLIOGRAFICAS}

ALVES, D.B. 1987 - Desenvolvimento da metodologia de preparação de amostras para análise difratométrica de argilominerais no CENPES, PETROBRAS, Bol. 1(2) p. 157-175.

AMERICAN SOCIETY FOR TESTING MATERIALS (ASTM) - Tabela de dados, pa ra identificação de minerais ao Raios-X, separata, p. 233-263. BROWN, G. 1961 - The X-Ray identification and crystal structures of clay minerals. London, Mineralogical Society, separata, p.111-486. RAMOS, D.N. \& FORMOSO, M.L.L. 1975 - Argilominerais das rochas sedi mentares da B. Paraná, CENPES, DEXPRO, DIVEX, RJ, vol. 75, p. 17-47. Mapeamento Geológico das Folhas de Camobi e Santa Maria, UFSM, 1:50.000. 